\title{
Volumetric and Functional Recovery of the Remnant Liver After Major Liver Resection with Prior Portal Vein Embolization
}

\author{
Recovery After PVE and Liver Resection
}

\author{
Jacomina W. van den Esschert • Wilmar de Graaf • Krijn P. van Lienden • \\ Olivier R. Busch • Michal Heger • Otto M. van Delden • Dirk J. Gouma • \\ Roelof J. Bennink • Johan S. Laméris • Thomas M. van Gulik
}

Received: 31 March 2009/Accepted: 11 May 2009/Published online: 28 May 2009

(C) 2009 The Author(s). This article is published with open access at Springerlink.com

\begin{abstract}
Introduction Portal vein embolization is an accepted method to increase the future remnant liver preoperatively. The aim of this study was to assess the effect of preoperative portal vein embolization on liver volume and function 3 months after major liver resection.

Materials and methods This is a retrospective case-control study. Data were collected of patients who underwent portal vein embolization prior to (extended) right hemihepatectomy and of control patients who underwent the same type of resection without prior portal vein embolization. Liver volumes were measured by computed tomography volumetry before portal vein embolization, before liver resection, and 3 months after liver resection. Liver function was assessed by hepatobiliary scintigraphy before and 3 months after liver resection.

Results Ten patients were included in the embolization group and 13 in the control group. Groups were comparable for gender, age, and number of patients with a compromised liver. The mean future remnant liver volume was $33.0 \pm 8.0 \%$ prior to portal vein embolization in the embolization group and $45.6 \pm 9.1 \%$ in the control group $(p<0.01)$. Prior to surgery, there were no significant differences in future remnant liver volume and function between the groups. Three months postoperatively, the mean remnant liver volume was $81.9 \pm 8.9 \%$ of the initial total liver volume in the embolization group and $79.4 \pm 11.0 \%$ in the control group $(p>0.05)$. Remnant liver function increased up to $88.1 \pm 17.4 \%$ and $83.3 \pm 14 \%$ respectively of the original total liver function $(p>0.05)$.

Conclusion Preoperative portal vein embolization does not negatively influence postoperative liver regeneration assessed 3 months after major liver resection.
\end{abstract}

No grant support.

Paper presented at the SSAT, Chicago, June 1, 2009.

J. W. van den Esschert • W. de Graaf • O. R. Busch • M. Heger •

D. J. Gouma $\cdot$ T. M. van Gulik $(\bowtie)$

Department of Surgery, Academic Medical Center,

IWO-1, Meibergdreef 9,

1105 AZ Amsterdam, The Netherlands

e-mail: t.m.vangulik@amc.uva.nl

K. P. van Lienden · O. M. van Delden·J. S. Laméris Department of Radiology, Academic Medical Center,

Amsterdam, The Netherlands

R. J. Bennink

Department of Nuclear Medicine, Academic Medical Center, Amsterdam, The Netherlands
Keywords CT volume · Liver - Surgery

Interventional radiography $\cdot$ Liver regeneration

$\begin{array}{ll}\text { Abbreviations } \\ \text { FRL } & \text { Future remnant liver } \\ \text { FRLF } & \text { Future remnant liver function } \\ \text { FRLV } & \text { Future remnant liver volume } \\ \text { HBS } & \text { Hepatobiliary scintigraphy } \\ \text { PVE } & \text { Portal vein embolization } \\ \text { RLF } & \text { Remnant liver function } \\ \text { RLV } & \text { Remnant liver volume } \\ \text { TLF } & \text { Total liver function } \\ \text { TLV } & \text { Total liver volume } \\ \text { TV } & \text { Tumor volume }\end{array}$




\section{Introduction}

Portal vein embolization (PVE) has been widely accepted as an effective means to increase the future remnant liver volume (FRLV) in patients requiring extensive liver resection. The safety and efficacy of PVE have been confirmed by several studies and a recent meta-analysis. ${ }^{1-4}$ PVE induces atrophy of the ipsilateral liver segments with concomitant compensatory hypertrophy of the future remnant liver (FRL). Preoperative PVE is recommended when the FRLV is less than $30-40 \%$ of the total liver volume (TLV) as determined by computed tomography (CT) volumetry, depending on the presence of underlying liver disease (e.g., steatosis, cholestasis).,

Liver regeneration is generally assessed by CT volumetry. Liver volume, however, does not necessarily represent liver function during liver regeneration. ${ }^{7,8}$ Liver function can accurately be assessed by technetium- $99 \mathrm{~m}$ mebrofenin hepatobiliary scintigraphy $\left({ }^{99 \mathrm{~m}} \mathrm{Tc}-\mathrm{meb}\right.$ rofenin HBS). ${ }^{7,9}$

The underlying mechanism of liver regeneration after partial liver resection or PVE is not fully understood. One suggested trigger for regeneration of the nonembolized liver lobes after PVE or resection is the instant increase in portal blood flow to the FRL. ${ }^{10-12}$ When right PVE is performed, the portal blood flow is preoperatively diverted to the left liver lobes. As a consequence, minimal changes in portal blood flow are induced at the time of partial liver resection and therefore, this trigger for posthepatectomy liver regeneration is lacking. Our hypothesis is therefore that preoperative PVE might hamper postoperative liver regeneration. The aim of this study was to evaluate the effect of preoperative PVE on postoperative liver volume and function 3 months after major liver resection.

\section{Materials and Methods}

Patients

Eighteen patients underwent PVE of the right portal system prior to (extended) right hemihepatectomy at our institution between January 2005 and November 2007. Only those patients in whom a complete set of CT scans was obtained were included in the study, i.e., a four-phase CT scan prior to PVE, 3-4 weeks after PVE (before liver resection), and 3 months after liver resection $(n=10)$. In all the patients, HBS was performed before PVE and in nine patients 3 months after liver resection.

Patients who had undergone (extended) right hemihepatectomy without prior PVE in the same period and of whom a CT scan had been obtained prior to and 3 months after liver resection were included in the control group $(n=$
13). Twelve of the 13 patients underwent HBS prior to PVE, which was repeated 3 months after liver resection in 11 patients. Patient characteristics, including gender, age, and number of patients with a compromised liver were compared for both groups.

Indications for surgery in the control group were colorectal metastasis $(n=5)$, hilar cholangiocarcinoma $(n=$ $4)$, hepatocellular carcinoma $(n=1)$, and other metastases $(n=3)$. In the PVE group, the indications were colorectal metastasis $(n=5)$, hilar cholangiocarcinoma $(n=1)$, hepatocellular carcinoma $(n=3)$, and neuroendocrine tumor $(n=1)$. Postoperative complications were subdivided into "minor" (grades I and II) or "major" (grades III, IV, V) according to the revised 2004 Clavien classification. ${ }^{13}$

\section{CT Volumetry}

Liver volumes were measured using CT. The total liver, the FRL, and tumor mass were manually delineated on each 5$\mathrm{mm}$ slide of the portal phase images. The TLV, tumor volume (TV), and FRLV were calculated using dedicated software (Mx-View 3.52, Philips Medical Systems, The Netherlands; Fig. 1). The percentage FRLV before PVE was calculated by: ${ }^{14}$

$$
\% \mathrm{FRLV}_{\text {pre-PVE }}=\left(\frac{\mathrm{FRLV}_{\text {pre-PVE }}}{(\mathrm{TLV}-\mathrm{TV})_{\text {pre-PVE }}}\right) \times 100 \%
$$

To obtain the percentage, FRLV after PVE was computed by:

$\% \mathrm{FRLV}_{\text {pre-op }}=\left(\frac{\mathrm{FRLV}_{\text {pre-op }}}{(\mathrm{TLV}-\mathrm{TV})_{\mathrm{pre}-\mathrm{PVE}}}\right) \times 100 \%$

The remnant liver volume (RLV) 3 months after liver resection was calculated as a percentage of the initial total functional liver volume (TLV-TV):

$\% \mathrm{RLV}_{3 \text { months }}=\left(\frac{\mathrm{RLV}}{(\mathrm{TLV}-\mathrm{TV})_{\mathrm{pre}-\mathrm{PVE}}}\right) \times 100 \%$

Hepatobiliary Scintigraphy

HBS was performed using ${ }^{99 \mathrm{~m}} \mathrm{Tc}-\mathrm{meb}$ rofenin as previously described. $^{7}$ Briefly, after injection of $85 \mathrm{MBq}$ of ${ }^{99 \mathrm{~m}} \mathrm{Tc}$ mebrofenin (Bridatec; GE-Amersham Health), dynamic images were acquired with a $\gamma$-camera (Diacam, Siemens, Milwaukee, WI, USA) for $60 \mathrm{~min}$. During the first $10 \mathrm{~min}$, 60 frames of $10 \mathrm{~s}$ were acquired (liver uptake phase) followed by 50 frames of 1 min (liver excretion phase). Total hepatic ${ }^{99 \mathrm{~m}}$ Tc-mebrofenin uptake rate was calculated as described by Ekman et al. ${ }^{15}$ On preoperative scan, 

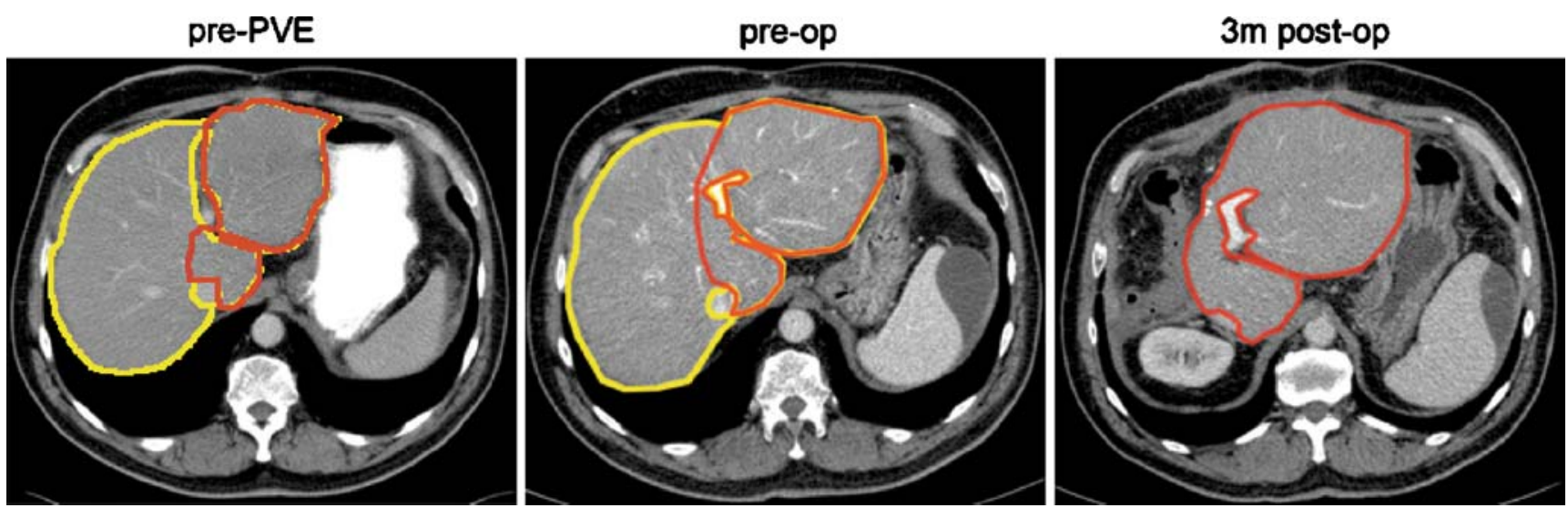

Figure $1 \mathrm{CT}$ cross section of the liver showing total liver (yellow delineation) and the future remnant liver (red delineation). CT volumetry showed that the future remnant liver was markedly increased 3 weeks after portal vein embolization (pre-op, $507 \mathrm{ml}$ ) compared to before portal vein embolization (pre-PVE, $392 \mathrm{ml}$ ). Three

regions of interest (ROIs) were drawn around the total liver, the heart (serving as blood pool), and the total field of view. From these ROIs, three time-activity curves were generated. The total hepatic ${ }^{99 \mathrm{~m}} \mathrm{Tc}$-mebrofenin uptake rate, representing total liver function (TLF), was calculated as percent per minute (of the injected dose) based on these three parameters. Calculations of the hepatic ${ }^{99 \mathrm{~m}} \mathrm{Tc}$-mebrofenin uptake rate were performed using measured values obtained between 150 and $350 \mathrm{~s}$ postinjection to ensure that hepatic uptake calculations were performed during a phase of homogenous distribution of the agent in the blood pool, before occurrence of the rapid phase of hepatic excretion. To compensate for differences in individual metabolic requirements, the TLF was divided by the body surface area and expressed as percent per minute per square meter.

\section{Portal Vein Embolization}

PVE was performed in patients in whom the estimated FRLV, based on CT volumetry, was $<30 \%$ in case of normal liver parenchyma and $<40 \%$ in patients with compromised liver parenchyma due to steatosis, cholestasis, or fibrosis. PVE was performed using the ipsilateral percutaneous transhepatic approach. After retrograde catheterization via a peripheral portal branch (segment 6 or 7), the right portal trunk and intrahepatic tributaries were occluded using a combination of polyvinyl alcohol particles (300 $500 \mu \mathrm{m}$, Cook, Bloomington, IN, USA) and platinum coils of various sizes (Tornado embolization microcoil, Cook).

\section{Statistical Analysis}

Statistical analysis was performed using Statistical Package for Social Sciences (SPSS, Chicago, IL, USA). Continuous variables were expressed as mean \pm standard deviation months after partial liver resection, the remnant liver volume almost reached its original total liver volume. For interpretation of the references to color in this figure legend, the reader is referred to the online version of this article.

(SD). An independent sample $t$ test was performed to assess the difference in future remnant liver volume and function between the two groups prior to surgery. A mixed analysis of variance was conducted to assess whether there were PVE and time differences in CT volumetry and HBS outcomes between the two groups after liver surgery. The correlation between variables was tested using the Pearson correlation coefficient $r$. All tests were two-tailed and differences were evaluated at the $5 \%$ level of significance.

\section{Results}

Patient characteristics are shown in Table 1. There were no significant differences between the two groups with respect to gender, age, and number of patients with a compromised liver.

The FRLV was based on the actual removed part of the liver. Prior to resection, the \%FRLV was calculated taking into account the maximum volume of liver that would need to be resected to achieve complete removal of all lesions. In some patients, the extent of the resection was less than expected based on intraoperative findings, resulting in a higher $\% \mathrm{FRLV}_{\text {pre-PVE}}$.

The $\% \mathrm{FRLV}_{\text {pre-PVE }}$ was $33.0 \pm 8.0 \%$ in the PVE group compared to a \%FRLV $\mathrm{Fre}_{\text {-op }} 45.6 \pm 9.1 \%$ in the control group ( $p=0.002$ ). Three to 4 weeks (mean 23 days) after PVE, the $\% F R L V$ pre-op increased to $41.6 \pm 9.5 \%$, resulting in no significant difference between the two groups prior to liver resection $(p=0.33)$. Liver scintigraphy showed a mean ${ }^{99 \mathrm{~m}} \mathrm{Tc}$-mebrofenin uptake rate in the total liver of $7.90 \pm$ $1.5 \% / \mathrm{min} / \mathrm{m}^{2}$ in the control group and $7.11 \pm 1.6 \% / \mathrm{min} / \mathrm{m}^{2}$ in the PVE group before any intervention $(p=0.24)$.

The increase in percentage remnant liver volume from preoperatively to 3 months after major liver surgery was not 
Table 1 Patient Characteristics of Patients Undergoing Liver Resection with (PVE Group) or Without (Control Group) Prior Portal Vein Embolization

\begin{tabular}{|c|c|c|c|}
\hline & PVE group $(n=10)$ & Control group $(n=13)$ & $p$ value \\
\hline Female/male & $6 / 4$ & $8 / 5$ & n.s. ${ }^{\text {b }}$ \\
\hline Mean age in years (range) & $56.1(49-74)$ & $55(39-71)$ & n.s. ${ }^{\mathrm{c}}$ \\
\hline Compromised/noncompromised & $6 / 4$ & $7 / 6$ & n.s. ${ }^{b}$ \\
\hline Standard/extended hemihepatectomy & $5 / 5$ & $10 / 3$ & n.s. ${ }^{b}$ \\
\hline Postoperative complications (minor/major ${ }^{\mathrm{a}}$ ) & $5(3 / 2)$ & $7(4 / 3)$ & n.s. ${ }^{b}$ \\
\hline Mean \pm SD \%FRL volume before PVE & $33.0 \pm 8.0$ & $45.6 \pm 9.1$ & $<0.01^{\mathrm{c}}$ \\
\hline Mean \pm SD $\%$ FRL volume preoperative & $41.7 \pm 9.5$ & $45.6 \pm 9.1$ & n.s. ${ }^{\mathrm{c}}$ \\
\hline Mean \pm SD \%FRL 3 months after liver resection & $81.9 \pm 8.9$ & $79.4 \pm 11.0$ & n.s. ${ }^{\mathrm{c}}$ \\
\hline Mean \pm SD FRL function before PVE & $7.1 \pm 1.6$ & $7.9 \pm 1.5$ & n.s. ${ }^{\mathrm{c}}$ \\
\hline Mean \pm SD FRL function 3 months after liver resection & $6.2 \pm 1.8$ & $6.5 \pm 2.1$ & n.s. ${ }^{\mathrm{c}}$ \\
\hline
\end{tabular}

Both groups were comparable for gender, age, number of patients with a compromised liver, postoperative complications, and preoperative future remnant liver volume. Future remnant liver volume before PVE was significantly smaller in the PVE group than in the control group, which was equalized 3-4 weeks after PVE. Three months after major liver resection, the remnant liver gained up to $80 \%$ of its initial total functional liver volume in both groups

${ }^{a}$ According to the revised 2004 Clavien classification (7): minor = grades I and II; major = grades III and above

${ }^{\mathrm{b}}$ Pearson's chi-square test

${ }^{\mathrm{c}}$ Independent sample T-test

different between the two groups $(p=0.81)$. Three months after surgery, the mean RLV in the PVE group was $81.9 \pm$ $8.9 \%$ of the initial total liver volume compared to $79.4 \pm$ $11.0 \%$ in the control group ( $p=0.57$; Table 1 ; Fig. 2$)$. In addition, the postoperative increase in liver function did not differ between both groups $(p=0.471)$. Three months postoperatively, the RLF regained $88.1 \pm 17.4 \%$ of the

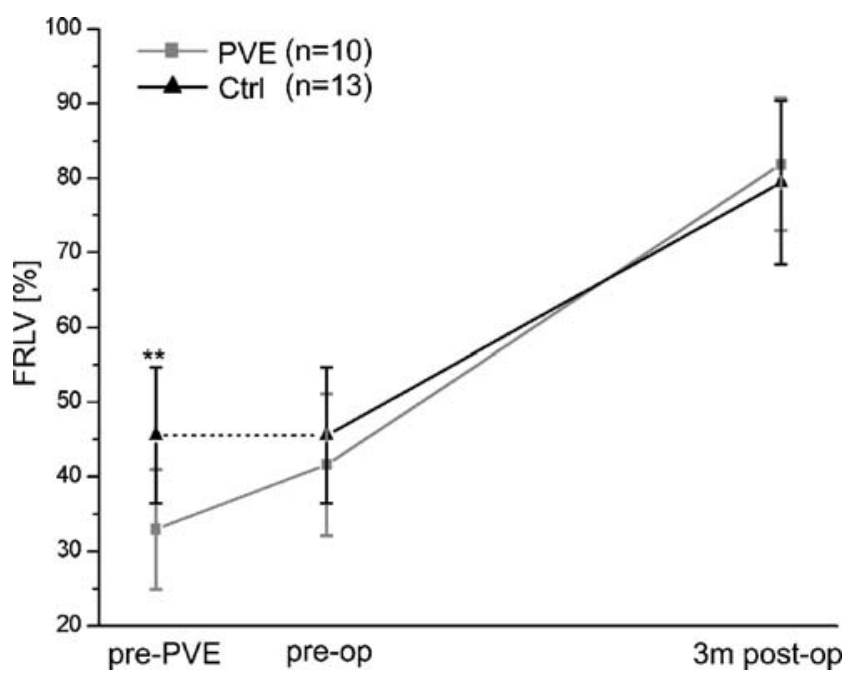

Figure 2 CT volumetry data. Mean percentage of (future) remnant liver volume $(F R L V)$ in relation with initial total functional liver volume. Prior to PVE (pre-PVE), this percentage was significantly lower in the group requiring PVE $(* * p<0.01)$. Three to 4 weeks after PVE (pre-op), the FRLV increased with $8.7 \%$ in the PVE group, leading to comparable values in the two groups. Three months after partial liver resection $(3 \mathrm{~m}$ post-op), remnant liver volumes reached approximately $80 \%$ of initial total functional liver volume in both groups. original total liver function in the PVE group compared to $83.3 \pm 14 \%$ in the control group ( $p=0.50$; Fig. 3). No correlation was found between liver volume and function $(r=0.13, p=0.59)$.

\section{Discussion}

The main goal of this study was to evaluate the influence of PVE on volumetric and functional liver regeneration after

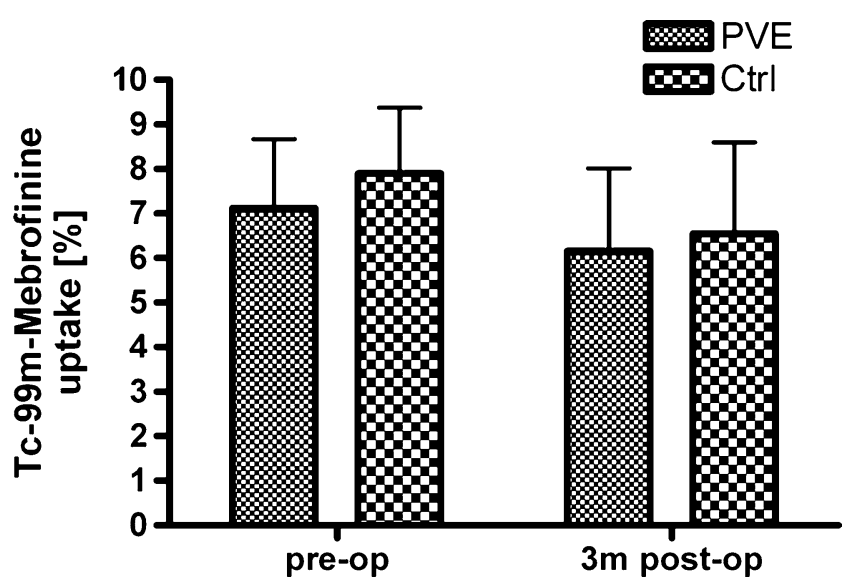

Figure 3 Uptake of ${ }^{99 \mathrm{~m}} \mathrm{Tc}$-mebrofenin by the total liver prior to any intervention and 3 months after partial liver resection. There were no significant differences in uptake between the PVE and the control groups at both time points. The remnant liver function reached $88.1 \%$ and $83,3 \%$, respectively, of the original total liver function in both groups $(p=0.50)$. 
major liver resection. CT volumetry was performed prior to PVE and surgery. The increase of the \%FRLV after PVE (\% FRLV $_{\text {pre-op-pre-PVE }}$ ) was $8.7 \%$ in 23 days. In a recent metaanalysis, a mean increase of $11.9 \%$ was reported 29 days after PVE. ${ }^{16}$ However, results between the various studies are difficult to compare due to substantial differences in the time interval between PVE and subsequent CT volumetry and the different techniques of embolization. For example, Farges et al. observed an increase in FRL of 16\% 48 weeks after PVE $^{17}$ whereas Elias et al. reported an increase of $13 \% 1$ month after PVE. ${ }^{18}$ Ribero et al. ${ }^{19}$ and Madoff et al. ${ }^{20}$ showed an increase of $8.8 \%$ and $7.7 \%, 2$ 8 and 2-4 weeks after PVE, respectively, using a calculation based on body surface area.

Three months after partial liver resection, the remnant liver volume regenerated to approximately $80 \%$ of its original total volume in both groups. Liver function increased to $83 \%$ in the control group and to $88 \%$ in the PVE group. There was no correlation between volumetric and functional recovery, confirming the postulation that liver volume does not necessarily reflect liver function during liver regeneration. ${ }^{7}$

To our knowledge, there are no studies that compared postoperative liver volume increase and functional increase after partial liver resection in patients with and without prior PVE. Although there could have been a difference in initial regenerative response following liver resection, our results show comparable restoration rates of liver volume 3 months after (extended) hemihepatectomy in both groups.

Most data on the process of hepatocyte regeneration have been obtained from animal or in vitro studies. The time course of liver regeneration after PVE and after partial liver resection appears to be similar as has been shown in a rat model. ${ }^{21}$ Although various mediators and pathways involved in liver regeneration have been described, the initial trigger of the entire process remains elusive. ${ }^{22-25}$ The instant change in portal blood flow after partial liver resection is believed to be a trigger for liver regeneration. Experimental studies have shown decreased posthepatectomy liver regeneration in rats receiving a portacaval shunt. $^{26,27}$ When performing PVE prior to surgery, the change in portal blood flow is negligible in case of a standard right hemihepatectomy and less profound in case of an extended right hemihepatectomy because the portal blood had already been diverted to the left portal vein at the time of PVE. Our study shows that the liver regenerates up to $80 \%$ of its original total liver volume 3 months after major liver resection, in spite of prior PVE.

One might speculate that instead of the change in portal blood flow, the change in arterial blood flow after hepatic resection induces liver regeneration. A study in rats showed that ligation of the hepatic artery alone did not affect liver regeneration. ${ }^{28}$ However, it is questionable whether the rat model is an appropriate surrogate model for studying the effects of altered hepatic arterial blood flow on liver regeneration or function. It is possible that the hypertrophy response of the remnant liver is slower after prior PVE in the first weeks after liver resection, but this ultimately did not result in dissimilar liver volumes after 3 months.

\section{Conclusion}

PVE does not hamper the regenerative capacity of the FRL after partial liver resection. The remnant liver regenerates up to approximately $80 \%$ of its initial total liver volume and over $83 \%$ of its original total liver function 3 months after major liver resection with or without prior PVE.

Open Access This article is distributed under the terms of the Creative Commons Attribution Noncommercial License which permits any noncommercial use, distribution, and reproduction in any medium, provided the original author(s) and source are credited.

\section{References}

1. Abdalla EK, Barnett CC, Doherty D, Curley SA, Vauthey JN. Extended hepatectomy in patients with hepatobiliary malignancies with and without preoperative portal vein embolization. Arch Surg. 2002;137(6):675-680. doi:10.1001/archsurg.137.6.675.

2. Azoulay D, Castaing D, Krissat J, Smail A, Hargreaves GM, Lemoine A, et al. Percutaneous portal vein embolization increases the feasibility and safety of major liver resection for hepatocellular carcinoma in injured liver. Ann Surg. 2000;232(5):665-672. doi:10.1097/00000658-200011000-00008.

3. Azoulay D, Castaing D, Smail A, Adam R, Cailliez V, Laurent A, et al. Resection of nonresectable liver metastases from colorectal cancer after percutaneous portal vein embolization. Ann Surg. 2000;231(4):480-486. doi:10.1097/00000658-200004000-00005.

4. Abulkhir A, Limongelli P, Healey AJ, Damrah O, Tait P, Jackson $\mathrm{J}$, et al. Preoperative portal vein embolization for major liver resection: a meta-analysis. Ann Surg. 2008;247(1):49-57. doi:10.1097/SLA.0b013e31815f6e5b.

5. Vauthey JN, Chaoui A, Do KA, Bilimoria MM, Fenstermacher MJ, Charnsangavej C, et al. Standardized measurement of the future liver remnant prior to extended liver resection: methodology and clinical associations. Surgery 2000;127(5):512-519. doi: $10.1067 / \mathrm{msy} .2000 .105294$.

6. Heymsfield SB, Fulenwider T, Nordlinger B, Barlow R, Sones P, Kutner M. Accurate measurement of liver, kidney, and spleen volume and mass by computerized axial tomography. Ann Intern Med. 1979;90(2):185-187.

7. Bennink RJ, Dinant S, Erdogan D, Heijnen BH, Straatsburg IH, van Vliet $\mathrm{AK}$, et al. Preoperative assessment of postoperative remnant liver function using hepatobiliary scintigraphy. J Nucl Med. 2004;45(6):965-971.

8. Kwon AH, Matsui Y, Ha-Kawa SK, Kamiyama Y. Functional hepatic volume measured by technetium-99m-galactosyl-human serum 
albumin liver scintigraphy: comparison between hepatocyte volume and liver volume by computed tomography. Am J Gastroenterol. 2001;96(2):541-546. doi:10.1111/j.1572-0241.2001.03556.x.

9. Erdogan D, Heijnen BH, Bennink RJ, Kok M, Dinant S, Straatsburg IH, et al. Preoperative assessment of liver function: a comparison of $99 \mathrm{mTc}$-mebrofenin scintigraphy with indocyanine green clearance test. Liver Int. 2004;24(2):117-123. doi:10.1111/j.1478-3231.2004.00901.x.

10. Yokoyama Y, Nagino M, Nimura Y. Mechanisms of hepatic regeneration following portal vein embolization and partial hepatectomy: a review. World J Surg. 2007;31(2):367-374. doi:10.1007/s00268-006-0526-2.

11. Sato Y, Koyama S, Tsukada K, Hatakeyama K. Acute portal hypertension reflecting shear stress as a trigger of liver regeneration following partial hepatectomy. Surg Today 1997;27(6):518 526. doi:10.1007/BF02385805.

12. Sato Y, Tsukada K, Hatakeyama K. Role of shear stress and immune responses in liver regeneration after a partial hepatectomy. Surg Today 1999;29(1):1-9. doi:10.1007/BF02482962.

13. Dindo D, Demartines N, Clavien PA. Classification of surgical complications: a new proposal with evaluation in a cohort of 6336 patients and results of a survey. Ann Surg. 2004;240(2):205-213. doi:10.1097/01.sla.0000133083.54934.ae.

14. Kubota K, Makuuchi M, Kusaka K, Kobayashi T, Miki K, Hasegawa K, et al. Measurement of liver volume and hepatic functional reserve as a guide to decision-making in resectional surgery for hepatic tumors. Hepatology 1997;26(5):1176-1181.

15. Ekman M, Fjalling M, Friman S, Carlson S, Volkmann R. Liver uptake function measured by IODIDA clearance rate in liver transplant patients and healthy volunteers. Nucl Med Commun. 1996;17(3):235-242. doi:10.1097/00006231-199603000-00011.

16. Abulkhir A, Limongelli P, Healey AJ, Damrah O, Tait P, Jackson $\mathrm{J}$, et al. Preoperative portal vein embolization for major liver resection: a meta-analysis. Ann Surg. 2008;247(1):49-57. doi:10.1097/SLA.0b013e31815f6e5b.

17. Farges O, Belghiti J, Kianmanesh R, Regimbeau JM, Santoro R, Vilgrain V, et al. Portal vein embolization before right hepatectomy: prospective clinical trial. Ann Surg. 2003;237(2):208-217. doi:10.1097/00000658-200302000-00010.
18. Elias D, Ouellet JF, De BT, Lasser P, Roche A. Preoperative selective portal vein embolization before hepatectomy for liver metastases: long-term results and impact on survival. Surgery 2002;131(3):294-299. doi:10.1067/msy.2002.120234.

19. Ribero D, Abdalla EK, Madoff DC, Donadon M, Loyer EM, Vauthey JN. Portal vein embolization before major hepatectomy and its effects on regeneration, resectability and outcome. Br J Surg. 2007;94(11):1386-1394. doi:10.1002/bjs.5836.

20. Madoff DC, Hicks ME, Abdalla EK, Morris JS, Vauthey JN. Portal vein embolization with polyvinyl alcohol particles and coils in preparation for major liver resection for hepatobiliary malignancy: safety and effectiveness - study in 26 patients. Radiology 2003;227(1):251-260. doi:10.1148/radiol.2271012010.

21. Takeuchi E, Nimura Y, Mizuno S, Nagino M, Shoji-Kawaguchi $\mathrm{M}$, Izuta $\mathrm{S}$, et al. Ligation of portal vein branch induces DNA polymerases alpha, delta, and epsilon in nonligated lobes. J Surg Res. 1996;65(1):15-24. doi:10.1006/jsre.1996.0337.

22. Fausto N. Liver regeneration. J Hepatol. 2000;32(Suppl 1):19-31. doi:10.1016/S0168-8278(00)80412-2.

23. Yokoyama Y, Nagino M, Nimura Y. Mechanisms of hepatic regeneration following portal vein embolization and partial hepatectomy: a review. World J Surg. 2007;31(2):367-374. doi:10.1007/s00268-006-0526-2.

24. Court FG, Wemyss-Holden SA, Dennison AR, Maddern GJ. The mystery of liver regeneration. Br J Surg. 2002;89(9):1089-1095. doi:10.1046/j.1365-2168.2002.02166.x.

25. Taub R. Liver regeneration: from myth to mechanism. Nat Rev Mol Cell Biol. 2004;5(10):836-847. doi:10.1038/nrm1489.

26. Rokicki M, Rokicki W. Liver regeneration in rats after complete and partial occlusion of the portal blood influx. Res Exp Med (Berl). 1993;193(5):305-313. doi:10.1007/BF02576238.

27. Hata Y, Yoshikawa Y, Une Y, Sasaki F, Nakajima Y, Takahashi H, et al. Liver regeneration following portacaval shunt in rats: $3^{\prime}, 5^{\prime}-$ cyclic AMP changes in plasma and liver tissue. Res Exp Med (Berl). 1992;192(2):131-136. doi:10.1007/BF02576267.

28. Vetelainen R, Dinant S, van Vliet A, van Gulik TM. Portal vein ligation is as effective as sequential portal vein and hepatic artery ligation in inducing contralateral liver hypertrophy in a rat model. J Vasc Interv Radiol. 2006;17(7):1181-1188. 